\title{
Enhanced Incorporation of 3-Hydroxy-4- Methylvalerate Unit into Biosynthetic Polyhydroxyalkanoate Using Leucine as a Precursor
}

\author{
Azusa Saika', Yoriko Watanabe', Kumar Sudesh², Hideki Abe $^{3}$ and Takeharu Tsuge ${ }^{1 *}$
}

\begin{abstract}
Ralstonia eutropha PHB 4 expressing Pseudomonas sp. 61-3 polyhydroxyalkanoate (PHA) synthase 1 (PhaC1 Ps $_{\mathrm{s}}$ ) synthesizes PHA copolymer containing 3-hydroxybutyrate (3HB) and a small amount ( 0.5 mol\%) of 3-hydroxy-4methylvalerate (3H4MV) from fructose as a carbon source. In this study, enhanced incorporation of 3H4MV into PHA was investigated using branched amino acid leucine as a precursor of 3H4MV. Leucine has the same carbon backbone as $3 \mathrm{H} 4 \mathrm{MV}$ and is expected to be a natural and self-producible precursor. We found that the incorporation of $3 \mathrm{H} 4 \mathrm{MV}$ was enhanced by the supplementation of excess amount $(10 \mathrm{~g} / \mathrm{L})$ of leucine in the culture medium. This finding indicates that 3H4MV can be derived from leucine. To increase metabolic flux to leucine biosynthesis in the host strain by eliminating the feedback inhibition, the cells were subjected to $N$-methyl- $N$ '-nitro$\mathrm{N}$-nitrosoguanidine (NTG) mutagenesis and leucine analog resistant mutants were generated. The mutants showed statistically higher $3 \mathrm{H} 4 \mathrm{MV}$ fraction than the parent strain without supplementing leucine. Additionally, by supplying excess amount of leucine, the mutants synthesized 3HB-based PHA copolymer containing 3.1 mol\% 3H4MV and 1.2 mol\% 3-hydroxyvalerate (3HV) as minor constituents, which significantly affected the thermal properties of the copolymer. This study demonstrates that it is possible to enhance the monomer supply of 3H4MV into PHA by manipulating leucine metabolism.
\end{abstract}

Keywords: polyhydroxyalkanoate copolymer, 3H4MV precursor, leucine analog resistant mutant

\section{Introduction}

Polyhydroxyalkanoate (PHA) is a kind of aliphatic polyester synthesized by a wide variety of microorganisms as intracellular storage and carbon source (Sudesh et al. 2000). It can be biosynthesized from renewable carbon sources such as sugars and plant oils, and can be completely biodegraded in the environment. PHA is expected to solve some environmental problems such as, excess emission of carbon dioxide, depletion of petroleum and environment pollution by waste plastics.

Poly $[(R)$-3-hydroxybutyrate], $\mathrm{P}(3 \mathrm{HB})$, is the most common PHA that bacteria synthesize. However, $\mathrm{P}$ $(3 \mathrm{HB})$ is a brittle and rigid material with low flexibility

\footnotetext{
* Correspondence: tsuge.t.aa@m.titech.ac.jp

'Department of Innovative and Engineered Materials, Tokyo Institute of

Technology, 4259 Nagatsuta, Midori-ku, Yokohama 226-8502, Japan

Full list of author information is available at the end of the article
}

because of its high crystallinity (Sudesh et al. 2000). Thus, the application of $\mathrm{P}(3 \mathrm{HB})$ is limited. The mechanical properties of $\mathrm{P}(3 \mathrm{HB})$ can be effectively improved by copolymerization with $(R)$-3-hydroxyalkanoate (3HA) monomers having bulky side chains such as $(R)$-3-hydroxyvalerate (3HV) (Bloembergen et al. 1986; Lee et al. 1996; Steinbüchel and Pieper 1992), (R)-3-hydroxyhexanoate (3HHx) (Fukui and Doi 1997; Shimamura et al. 1994; Tsuge et al. 2004) and longer 3HA (Matsusaki et al. 2000; Singh and Mallick 2009). The incorporation of such $3 \mathrm{HA}$ monomers lowers the crystallinity of 3HB-based copolymers due to obstacle by bulky side chain. In addition, the melting temperature of copolymer decreases with an increase in the fraction of bulky 3HA, whereas elongation at break is markedly increased (Sudesh et al. 2000). The incorporation of comonomers into $\mathrm{P}(3 \mathrm{HB})$ sequence

\section{SpringerOpen ${ }^{\circ}$}

(c) 2011 Saika; licensee Springer. This is an Open Access article distributed under the terms of the Creative Commons Attribution License (http://creativecommons.org/licenses/by/2.0), which permits unrestricted use, distribution, and reproduction in any medium, provided the original work is properly cited. 
depends on the substrate specificity of the polymerizing enzyme, PHA synthase (PhaC). To date, many PhaC genes $(p h a C)$ have been cloned from various microorganisms and the gene products were characterized partially (Rehm 2003). In particular, the PHA synthase of Pseudomonas sp. 61-3 (PhaC1 $1_{\mathrm{Ps}}$ ) has attracted much attention because of its unique substrate specificity towards 3HA monomers with chain lengths of 4-12 carbon atoms (Matsusaki et al. 1998, 2000). Pseudomonads have several PhaCs with different substrate specificity. Since the other PhaCs from pseudomonads are unable to polymerize $3 \mathrm{HB}$ unit, $\mathrm{PhaC} 1_{\mathrm{Ps}}$ has been useful for the synthesis of $3 \mathrm{HB}$ based PHA copolymer incorporating various types of 3HA.

Recently, it was shown that Ralstonia eutropha (currently designated Cupriavidus necator) strain $\mathrm{PHB}^{-4}$ expressing $p h a C 1_{\mathrm{Ps}}$ has the ability to produce a new type of PHA copolymer containing branched monomer unit, termed 3-hydroxy-4-methylvalerate (3H4MV, Figure 1a), from fructose as the sole carbon source (Tanadchangsaeng et al. 2009, 2010). Both 3H4MV and 3HHx are isomers that differ only in the side chain structure, whereby $3 \mathrm{H} 4 \mathrm{MV}$ has an iso-propyl group as the side chain whereas $3 \mathrm{HHx}$ has an $n$-propyl group. Therefore, $\mathrm{P}(3 \mathrm{HB}-c o-3 \mathrm{H} 4 \mathrm{MV})$ and $\mathrm{P}(3 \mathrm{HB}-c o-3 \mathrm{HHx})$ copolymers showed similar mechanical and thermal properties (Tanadchangsaeng et al. 2009, 2010). The 3H4MV fraction of PHA produced from fructose by $R$. eutropha $\mathrm{PHB}^{-} 4$ expressing phaC $1_{\mathrm{Ps}}$ was only $0.5 \mathrm{~mol} \%$, but it can be increased up to $46 \mathrm{~mol} \%$ by feeding 4-methylvalerate $(4 \mathrm{MV})$ as a $3 \mathrm{H} 4 \mathrm{MV}$ precursor. However, since $4 \mathrm{MV}$ is a costly and toxic precursor, an alternative method to produce $\mathrm{P}(3 \mathrm{HB}-\mathrm{co}-3 \mathrm{H} 4 \mathrm{MV})$ from abundant and inexpensive renewable resources is desirable.

In this study, PHA containing $3 \mathrm{H} 4 \mathrm{MV}$ unit was synthesized by $R$. eutropha $\mathrm{PHB}^{-} 4$ expressing $p h a C 1_{\mathrm{Ps}}$ from fructose with or without the addition of branched amino acid, leucine, as a precursor of $3 \mathrm{H} 4 \mathrm{MV}$ unit. Because leucine has the same carbon backbone as

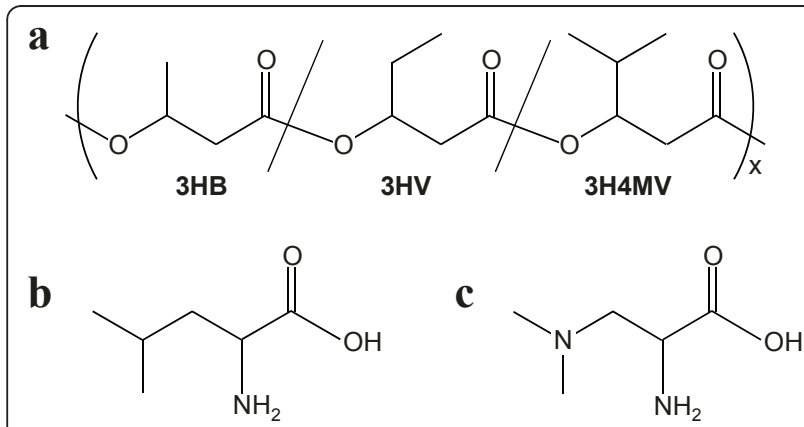

Figure 1 Structures of (a) $\mathrm{P}(3 \mathrm{HB}-\mathrm{co}-3 \mathrm{HV}-\mathrm{co}-3 \mathrm{H} 4 \mathrm{MV})$, (b) leucine, and (c) 4-azaleucine (leucine analog).
3H4MV (Figure 1b), it is expected to be useful as a natural metabolite precursor of $3 \mathrm{H} 4 \mathrm{MV}$. In addition, mutants that are resistant to leucine analog were generated by random chemical mutagenesis and characterized for their ability to incorporate $3 \mathrm{H} 4 \mathrm{MV}$ into PHA. This study demonstrates for the first time that it is possible to enhance the monomer supply of $3 \mathrm{H} 4 \mathrm{MV}$ into PHA by manipulating leucine metabolism.

\section{Materials and methods}

\section{Bacterial strains and plasmid}

PHA-negative mutant $R$. eutropha $\mathrm{PHB}^{-4}$ (DSM541) was employed as host strain for PHA synthesis (Schlegel et al. 1970). The recombinant plasmid pBBR1"C $1_{\mathrm{Ps}} \mathrm{AB}_{\mathrm{Re}}$ containing PHA synthase gene from Pseudomonas sp. 61-3 ( $\left.p h a C 1_{\mathrm{Ps}}\right)$ and monomer supplying enzyme genes from $R$. eutropha ( $p h a A B_{\mathrm{Re}}$ ) was transformed into the host strain by transconjugation (Tsuge et al. 2005). Leucine analog resistant mutants of $R$. eutropha $\mathrm{PHB}^{-} 4$ were generated according to the method described below.

\section{Generation of leucine analog resistant mutants}

R. eutropha $\mathrm{PHB}^{-4} 4$ expressing phaC1 $1_{\mathrm{Ps}}$ was grown in 1.7 $\mathrm{mL}$ Nutrient-Rich (NR) medium (10 g of Bacto trypton, $2 \mathrm{~g}$ of yeast extract and $10 \mathrm{~g}$ of meat extract per liter of distilled water) with $50 \mu \mathrm{g} / \mathrm{mL}$ kanamycin at $30^{\circ} \mathrm{C}$ for 24 $h$. The cells were harvested by centrifugation and then suspended in $2.5 \mathrm{~mL}$ potassium phosphate buffer (100 $\mathrm{mM}, \mathrm{pH}$ 7.0). Suspended cells were treated with $10 \mu \mathrm{L}$ $N$-methyl- $N$ '-nitro- $N$-nitrosoguanidine (NTG, $10 \mathrm{mg} / \mathrm{mL}$ stock solution of dimethyl sulfoxide) for $30 \mathrm{~min}$ at $30^{\circ} \mathrm{C}$. NTG treated cells were harvested and washed three times with NR medium. Then, the cells were resuspended in NR medium and $100 \mu \mathrm{L}$ cell suspended solution was inoculated into $1.7 \mathrm{~mL} \mathrm{NR}$ medium containing $50 \mu \mathrm{g} / \mathrm{mL}$ kanamycin and cultivated at $30^{\circ} \mathrm{C}$ for $24 \mathrm{~h}$. The recovered cells were spread on agar plate of mineral salt (MS) medium $\left(9 \mathrm{~g}\right.$ of $\mathrm{Na}_{2} \mathrm{HPO}_{4} \cdot 12 \mathrm{H}_{2} \mathrm{O}, 1.5 \mathrm{~g}$ of $\mathrm{KH}_{2} \mathrm{PO}_{4}, 0.5 \mathrm{~g}$ of $\mathrm{NH}_{4} \mathrm{Cl}, 0.2 \mathrm{~g}$ of $\mathrm{MgSO}_{4} \cdot 7 \mathrm{H}_{2} \mathrm{O}$ and 1 $\mathrm{mL}$ of trace element solution per liter of distilled water) (Kato et al. 1996) containing $1.5 \mathrm{~g} / \mathrm{L}$ 4-aza-DL-leucine dihydrochloride (Sigma Aldrich, St Louis, MO, USA, Figure 1c) as a leucine analog. After 2 days of incubation, colonies appeared on the selective agar plate which showed resistance to the leucine analog.

\section{HPLC assay of 3H4MV content in mutants}

The $3 \mathrm{H} 4 \mathrm{MV}$ content in leucine analog resistant mutants was measured by high-performance liquid chromatography (HPLC). Leucine analog resistant mutants were inoculated into $600 \mu \mathrm{L}$ MS medium supplemented with $20 \mathrm{~g} / \mathrm{L}$ fructose and $50 \mu \mathrm{g} / \mathrm{mL}$ kanamycin in $1.2 \mathrm{~mL}$ wells of 96 well plate. After sealing the plate with an air 
permeable film, the mutants were cultivated at $30^{\circ} \mathrm{C}$ for $72 \mathrm{~h}$ by shaking in a reciprocal shaker (130 strokes/ min). At the end of the cultivation period, the supernatant was discarded after the mutant cells were pelleted by centrifugation. Finally, the cell pellets in the 96-well plate were dried at $55^{\circ} \mathrm{C}$ for 3 days.

The sample for HPLC assay was prepared by alkaline treatment, the details of which are to be published elsewhere. The method is briefly described here. The dried cell pellets were treated with $200 \mu \mathrm{L}$ of $1 \mathrm{~N} \mathrm{NaOH}$ at $100^{\circ} \mathrm{C}$ for $3 \mathrm{~h}$ in a 96-well plate hermetically heat-sealed by polypropylene/aluminum film. The plate was then cooled to room temperature before adding $200 \mu \mathrm{L}$ of $1 \mathrm{~N} \mathrm{HCl}$ to the cell lysate for neutralization. This sample was filtered using a $0.45 \mu \mathrm{m}$ pore sized PTFE membrane filter plate, and the filtrates were collected into a new 96-well plate. By the alkaline treatment, the hydrolyzed 3 HAs were converted to the corresponding trans-2-alkenoic acids.

HPLC analysis was performed using an LC-10Avp system (Shimadzu, Kyoto, Japan) with an ion-exclusion column, Fast Acid Analysis (100 mm $\times 7.8 \mathrm{~mm}$ I.D., BioRad, Hercules, CA, USA), at $60^{\circ} \mathrm{C} . \mathrm{H}_{2} \mathrm{SO}_{4}(0.014 \mathrm{~N})$ with $12 \% \mathrm{CH}_{3} \mathrm{CN}$ was used as the mobile phase at a flow rate of $0.7 \mathrm{~mL} / \mathrm{min}$. The chromatograms were recorded at $210 \mathrm{~nm}$ by a UV detector because trans-2-alkenoic acids have strong UV absorption.

\section{PHA biosynthesis}

R. eutropha $\mathrm{PHB}^{-4}$ expressing phaC $1_{\mathrm{Ps}}$ and its leucine analog resistant mutants were cultured in a $500-\mathrm{mL}$ shaking flask (130 strokes/min) containing $100 \mathrm{~mL} \mathrm{MS} \mathrm{med-}$ ium, in which nitrogen source is limited for cell growth as described above, supplemented with $20 \mathrm{~g} / \mathrm{L}$ fructose at $30^{\circ}$ $\mathrm{C}$ for $72 \mathrm{~h}$. In all cases, $50 \mu \mathrm{g} / \mathrm{mL}$ kanamycin was added to the medium to maintain the plasmid stability. Five amino acids, L-leucine (L-Leu), L-valine (L-Val), L-isoleucine (LIle), L-threonine (L-Thr, Kanto Chemical, Tokyo, Japan) and D-leucine (D-Leu, Wako Pure Chemical, Osaka, Japan), were supplemented into MS medium to examine their ability to function as $3 \mathrm{H} 4 \mathrm{MV}$ precursor. The cultivated cells were harvested by centrifugation and washed with distilled water to remove the medium components before being lyophilized.

\section{PHA analyses}

PHA contents and composition were determined by gas chromatography (GC14B, Shimadzu, Kyoto, Japan) with flame ionization detector and gas chromatography-mass spectrometry (GCMS-QC 2010, Shimadzu, Kyoto, Japan). Approximately $30 \mathrm{mg}$ lyophilized cells were methanolyzed in the presence of $15 \%$ sulfuric acid before analysis (Kato et al. 1996).
PHA was extracted from lyophilized cells with chloroform at room temperature, and purified by reprecipitation into methanol. Molecular weight was determined by gel permeation chromatography (10A GPC system, Shimazdu, Kyoto, Japan). Approximately $1 \mathrm{mg}$ extracted polymer was dissolved in $1 \mathrm{~mL}$ chloroform, and analyzed at a column temperature of $40^{\circ} \mathrm{C}$. Polystyrene standards with a low polydispersity were used to make the calibration curve.

PHA films for thermal analysis were prepared by solvent casting method. For this, the extracted and purified PHA was dissolved in chloroform and the polymer solution was poured into Petri dishes. The solvent was evaporated at room temperature and then the films were aged for at least three weeks to reach equilibrium crystallinity prior to analysis. For differential scanning calorimetric analysis, 2-3 $\mathrm{mg}$ of the PHA film was encapsulated in aluminum pans and analyzed with a Perkin-Elmer Pyris 1 DSC (Perkin-Elmer, Waltham, MA, USA) in the temperature range of -50 to $200^{\circ} \mathrm{C}$ at a heating rate of $20^{\circ} \mathrm{C} / \mathrm{min}$ under nitrogen atmosphere.

\section{Results}

\section{Effect of Amino Acid Supplementation on 3H4MV} Fraction

Because the carbon back bone of $3 \mathrm{H} 4 \mathrm{MV}$ is the same as that of branched amino acid leucine (Figure 1), we expected that leucine and its structurally related amino acids could function as $3 \mathrm{H} 4 \mathrm{MV}$ precursors. To evaluate the feasibility of 3H4MV provision from amino acids, $R$. eutropha $\mathrm{PHB}^{-} 4$ expressing phaC1 $1_{\mathrm{Ps}}$ was cultivated in MS plus fructose medium supplemented with $10 \mathrm{~g} / \mathrm{L}$ of various amino acids. Table 1 shows the result of cultivation. The dry cell weights increased with the addition of amino acids except for L-valine and D-leucine. L-Valine has been used for PHA production (Fujita et al. 1993, Kimura et al. 2003); however, effect of high concentration of L-valine $(10 \mathrm{~g} / \mathrm{L})$ on the cell growth has not been reported previously. L-Isoleucine is known to function as a $3 \mathrm{HV}$ precursor in $R$. eutropha (Steinbüchel and Pieper 1992). Our result also showed that the addition of L-isoleucine enhanced the $3 \mathrm{HV}$ fraction to $7.7 \mathrm{~mol} \%$. The same effect was also demonstrated by L-threonine (Steinbüchel and Pieper 1992), but no enhancement of $3 \mathrm{HV}$ was seen in our study. As for $3 \mathrm{H} 4 \mathrm{MV}$, a very small amount of $3 \mathrm{H} 4 \mathrm{MV}(0.5 \mathrm{~mol} \%)$ was incorporated into PHA when no amino acids were supplemented. Supplementation of L-isoleucine and L-threonine also showed no effect on $3 \mathrm{H} 4 \mathrm{MV}$ enhancement. However, L-leucine supplementation showed a slightly increased $3 \mathrm{H} 4 \mathrm{MV}$ fraction $(0.9 \mathrm{~mol} \%)$, suggesting that L-leucine (hereinafter referred to as leucine) is a potent candidate of $3 \mathrm{H} 4 \mathrm{MV}$ precursor. 
Table 1 PHA biosynthesis by $R$. eutropha PHB-4 expressing phaC1 $1_{\mathrm{Ps}}$ with the supplementation of various amino acids

\begin{tabular}{|c|c|c|c|c|c|}
\hline \multirow[b]{2}{*}{ Amino acid } & \multirow[t]{2}{*}{ Dry cell weight $(\mathrm{g} / \mathrm{L})$} & \multirow[t]{2}{*}{ PHA content (wt\%) } & \multicolumn{3}{|c|}{ PHA composition (mol\%) ${ }^{a}$} \\
\hline & & & $3 \mathrm{HB}$ & $3 \mathrm{HV}$ & $3 \mathrm{H} 4 \mathrm{MV}$ \\
\hline none & 1.6 & 53 & 99.1 & 0.4 & 0.5 \\
\hline L-Val & trace $^{b}$ & - & - & - & - \\
\hline L-Leu & 7.2 & 29 & 98.8 & 0.3 & 0.9 \\
\hline L-lle & 5.7 & 17 & 92.3 & 7.7 & 0 \\
\hline L-Thr & 7.6 & 43 & 99.3 & 0.4 & 0.3 \\
\hline D-Leu & $\operatorname{trace}^{\mathrm{b}}$ & - & - & - & - \\
\hline
\end{tabular}

Cells were cultured in MS plus fructose $(20 \mathrm{~g} / \mathrm{L})$ medium supplemented with each amino acid (10 g/L). The results are the average of three independent cultivations (the standard deviations were less than $5 \%$ of the mean).

a PHA composition was determined by GC.

${ }^{\mathrm{b}}$ less than $0.1 \mathrm{~g} / \mathrm{L}$.

\section{PHA Production by Leucine Analog Resistant Mutants}

From the result of leucine supplementation, it was speculated that $3 \mathrm{H} 4 \mathrm{MV}$ provision might be increased by increasing the metabolic flux to leucine biosynthesis, without the use of $3 \mathrm{H} 4 \mathrm{MV}$ precursor. However, leucine biosynthesis pathway is known to be strictly regulated by end product feedback inhibition. To eliminate the feedback inhibition, we aimed to generate leucine analog resistant mutants of $R$. eutropha $\mathrm{PHB}^{-} 4$ harboring phaC1 $1_{\mathrm{Ps}}$ by NTG mutagenesis, using the same approach that was used for the generation of L-leucine producers of E. coli. (Nakano et al. 1996)

More than a thousand leucine analog resistant mutants of $R$. eutropha $\mathrm{PHB}^{-} 4$ harboring phaC1 $1_{\mathrm{Ps}}$ were generated by the mutagenesis. These mutants were cultured in 96-deep well plate with MS medium plus fructose as a sole carbon source to analyze the PHA composition by high-throughput HPLC. As a result, 440 leucine analog resistant mutants accumulated detectable amount of PHA. Figure 2 shows the comparison of average $3 \mathrm{H} 4 \mathrm{MV}$ fractions between $R$. eutropha $\mathrm{PHB}^{-} 4$ expressing phaC1 $1_{\mathrm{Ps}}$ (parent strain) and leucine analog resistant mutants. The average $3 \mathrm{H} 4 \mathrm{MV}$ fraction of the parent strain was $0.29 \mathrm{~mol} \%$ (number of repeated culture, $\mathrm{n}=20$ ) in this assay condition, whereas that of leucine analog resistant mutants showed 0.43 mol\% (number of analyzed colonies, $\mathrm{n}=440$ ), which showed a statistically significant increase in $3 \mathrm{H} 4 \mathrm{MV}$ fraction. The impaired leucine feedback system of these mutants resulted in increased $3 \mathrm{H} 4 \mathrm{MV}$ fraction due to the increased metabolic flux to leucine biosynthesis.

Four leucine analog resistant mutants showing significantly higher $3 \mathrm{H} 4 \mathrm{MV}$ fraction, designated as $1 \mathrm{~F} 2,6 \mathrm{C} 1$, $12 \mathrm{D} 1$ and $13 \mathrm{H} 3$, were selected for further characterization. These mutants were cultivated in shaken flasks containing $100 \mathrm{~mL}$ MS plus fructose medium for $72 \mathrm{~h}$ at $30^{\circ} \mathrm{C}$. Table 2 shows the result of cultivation and PHA composition determined by GC. These mutants showed approximately 2 -fold higher $3 \mathrm{H} 4 \mathrm{MV}$ fraction (up to $0.9 \mathrm{~mol} \%)$ than the parent strain $(0.5 \mathrm{~mol} \%)$. As for $3 \mathrm{HV}$ unit, the mutants (1.5-1.7 mol\%) showed up to 4-fold higher fraction than the parent strain $(0.4 \mathrm{~mol} \%)$. There was no significant effect on cell growth and PHA content among the four mutants and the parent strain.

\section{PHA Production by Mutants with Leucine Supplementation}

The maximum 3H4MV fraction achieved so far was less than 1 mol\% even by using leucine analog resistant mutants or feeding leucine as a $3 \mathrm{H} 4 \mathrm{MV}$ precursor. To further increase the $3 \mathrm{H} 4 \mathrm{MV}$ fraction, the above four mutants were cultured in MS plus fructose medium supplemented with excess amount of leucine $(10 \mathrm{~g} / \mathrm{L})$.

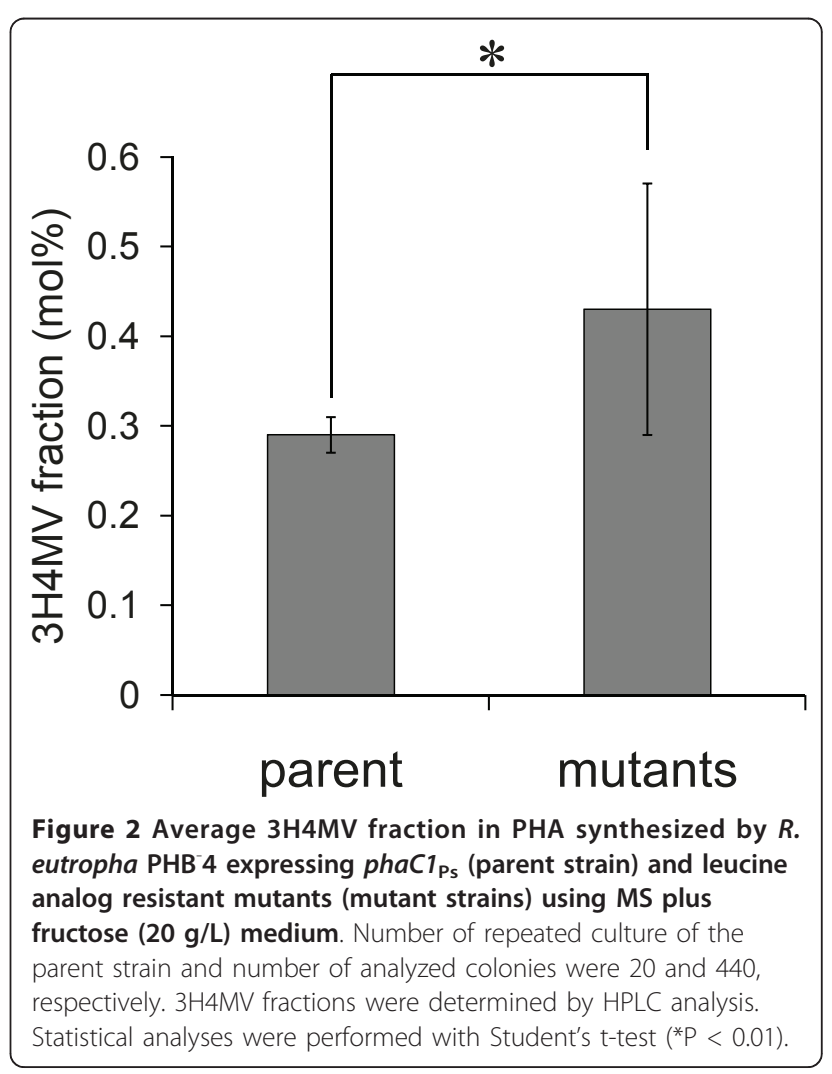


Table 2 PHA biosynthesis by $R$. eutropha PHB 4 expressing phaC1 $1_{\mathrm{Ps}}$ or the leucine analog resistant mutants from fructose as the sole carbon source

\begin{tabular}{cccccc}
\hline & Dry cell weight (g/L) & PHA content (wt\%) & \multicolumn{3}{c}{ PHA composition (mol\%) } \\
\cline { 4 - 6 } Strain & & & 3HB & 3HV & 3H4MV \\
\hline Parent $^{b}$ & 1.6 & 53 & 99.1 & 0.4 & 0.5 \\
$1 \mathrm{~F} 2^{c}$ & 1.5 & 53 & 97.6 & 1.6 & 0.8 \\
$6 \mathrm{C} 1^{c}$ & 1.7 & 55 & 97.6 & 1.5 & 0.9 \\
$12 \mathrm{D} 1^{c}$ & 1.6 & 51 & 97.4 & 1.7 & 0.9 \\
$13 \mathrm{H} 3^{c}$ & 1.7 & 51 & 97.4 & 1.7 & 0.9 \\
\hline
\end{tabular}

Cells were cultured in MS plus fructose $(20 \mathrm{~g} / \mathrm{L})$ medium. The results are the averages of three independent cultivations (the standard deviations were less than $5 \%$ of the mean).

a $\mathrm{PHA}$ composition was determined by GC.

${ }^{\mathrm{b}}$ R. eutropha $\mathrm{PHB}^{-4}$ expressing phaC $1_{\mathrm{Ps}}$.

c leucine analog resistant mutants.

Table 3 shows the result of cultivation. The parent strain showed 0.9 mol\% $3 \mathrm{H} 4 \mathrm{MV}$ fraction, whereas the mutants showed significantly increased 3H4MV fraction in the range of $2.5-3.0 \mathrm{~mol} \%$. Also, $3 \mathrm{HV}$ fractions were also increased to $1.0-1.4 \mathrm{~mol} \%$. The cell growth of the mutants was at the same level as the parent strain, but the PHA content was slightly increased. The combination of leucine analog resistant mutant and leucine supplementation was effective to increase 3H4MV fraction.

To examine the relationship between 3H4MV fraction and leucine concentration in the medium, the parent strain and the mutant $1 \mathrm{~F} 2$ were cultivated using various concentrations of leucine. The $3 \mathrm{H} 4 \mathrm{MV}$ fractions in PHA are compared in Figure 3a. Both strains showed an increase in $3 \mathrm{H} 4 \mathrm{MV}$ fraction with increasing leucine concentration from 5 to $10 \mathrm{~g} / \mathrm{L}$. The $3 \mathrm{H} 4 \mathrm{MV}$ fraction in the mutant $1 \mathrm{~F} 2$ reached $3 \mathrm{~mol} \%$ at $10 \mathrm{~g} / \mathrm{L}$ leucine, whereas the parent strain showed the maximum 3H4MV fraction at $12 \mathrm{~g} / \mathrm{L}$ leucine. Figures. $3 \mathrm{~b}$ and $3 \mathrm{c}$ show the PHA content and residual biomass of both strains, respectively. The PHA contents decreased with increasing leucine concentration due to the sufficient supply of nitrogen source. It is well known that PHA synthesis is repressed under nitrogen-rich condition (Sudesh et al,
2000). In contrast, production of residual biomass was prompted by excess amount of nitrogen derived from leucine. At the leucine concentration of up to $5 \mathrm{~g} / \mathrm{L}$, leucine was preferentially used for residual biomass production (Figure 3c). When the leucine concentration was more than $5 \mathrm{~g} / \mathrm{L}$, the residual biomass reached a plateau probably due to the shortage of some nutrition other than nitrogen source. Therefore, the excess leucine would be converted to $3 \mathrm{H} 4 \mathrm{MV}$, instead of residual biomass, at 5-12 $\mathrm{g} / \mathrm{L}$ of leucine concentration.

\section{Characterization of PHA Synthesized by Mutant 1F2}

Molecular weights and thermal properties of PHA synthesized by mutant $1 \mathrm{~F} 2$ in the presence of leucine were characterized. The $3 \mathrm{H} 4 \mathrm{MV}$ fractions were varied by changing leucine concentrations in the medium. Table 4 shows the molecular weights and thermal properties of the resulting PHA. The number average molecular weight $\left(M_{n}\right)$ and the weight average molecular weight $\left(M_{w}\right)$ decreased from $251 \times 10^{3}$ to $98 \times 10^{3}$ and $479 \times 10^{3}$ to $160 \times 10^{3}$, respectively, as leucine concentration increased from 0 to $10 \mathrm{~g} / \mathrm{L}$. The polydispersity indexes $\left(M_{w} / M_{n}\right)$ were in the range of 1.6-1.9. As the $3 \mathrm{HV}$ plus $3 \mathrm{H} 4 \mathrm{MV}$ fractions increased from 0 to $4.3 \mathrm{~mol}$

Table 3 PHA biosynthesis by R. eutropha PHB 4 expressing phaC1 $1_{\mathrm{Ps}}$ or leucine analog resistant mutants with the supplementation of $10 \mathrm{~g} / \mathrm{L}$ leucine

\begin{tabular}{cccccc}
\hline & Dry cell weight (g/L) & PHA content (wt\%) & \multicolumn{3}{c}{ PHA composition (mol\%) } \\
\cline { 4 - 6 } Strain & & & 3HB & 3HV & 3H4MV \\
\hline Parent $^{b}$ & 7.2 & 29 & 98.8 & 0.3 & 0.9 \\
$1 \mathrm{~F} 2^{c}$ & 7.1 & 34 & 95.8 & 1.2 & 3.0 \\
$6 \mathrm{C} 1^{c}$ & 7.2 & 36 & 96.5 & 1.0 & 2.5 \\
$12 \mathrm{D} 1^{c}$ & 7.3 & 35 & 95.8 & 1.4 & 2.8 \\
$13 \mathrm{H} 3^{c}$ & 7.2 & 35 & 95.9 & 1.3 & 2.8 \\
\hline
\end{tabular}

Cells were cultured in MS plus fructose $(20 \mathrm{~g} / \mathrm{L})$ medium supplemented with L-leucine $(10 \mathrm{~g} / \mathrm{L})$. The results are the averages of three independent cultivations (the standard deviations were less than $5 \%$ of the mean).

a PHA composition was determined by GC.

${ }^{\mathrm{b}} R$. eutropha $\mathrm{PHB}^{-4}$ expressing phaC $1_{\mathrm{Ps}}$.

${ }^{c}$ leucine analog resistant mutants. 


\section{a}
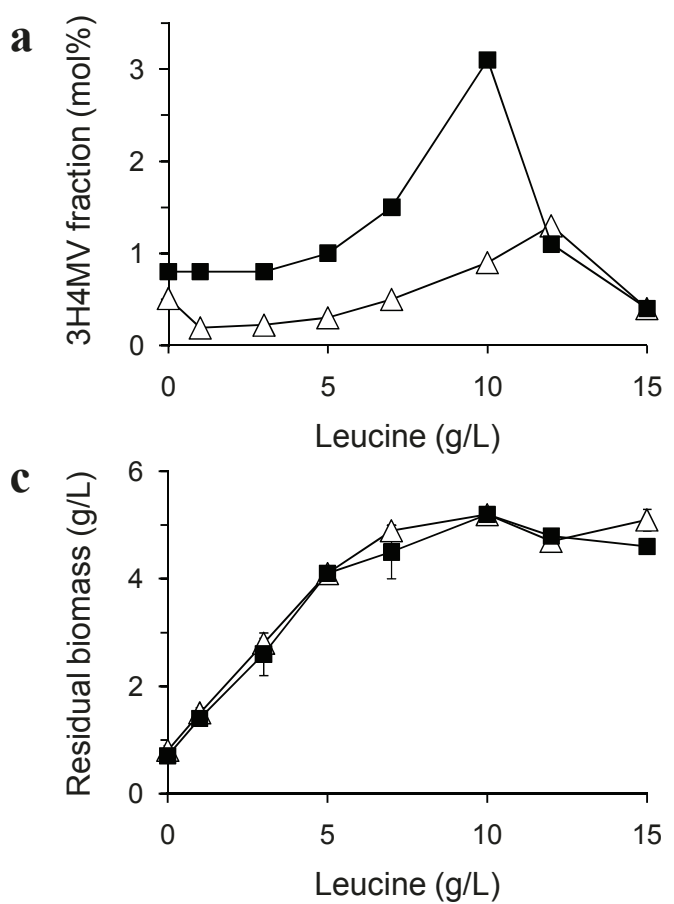

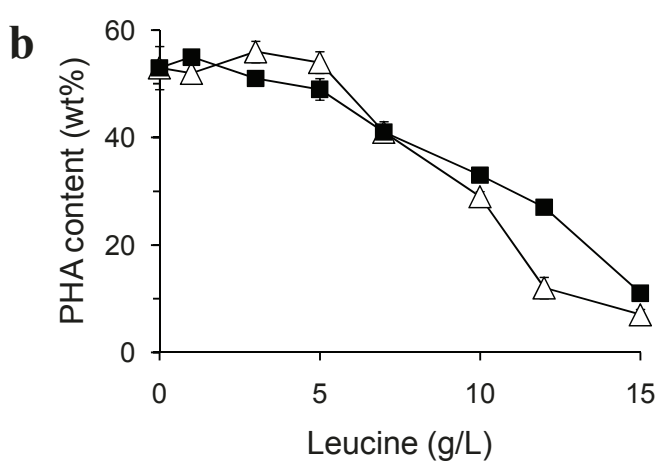

Figure 3 Cultivation of $R$. eutropha PHB 4 expressing phaC $1_{\mathrm{Ps}_{\mathrm{s}}}$ (open triangle) and the leucine analog resistant strain $1 \mathrm{~F} 2$ (closed square) in the presence of various concentration of L-leucine (0-15 g/L) and fructose (20 g/L). (a) 3H4MV fraction in PHA copolymers, (b) PHA contents in the cells, (c) residual biomass (obtained by subtracting PHA weight from dry cell weight).

$\%$, melting temperature $\left(T_{\mathrm{m}}\right)$ decreased drastically from $172^{\circ} \mathrm{C}$ to $137^{\circ} \mathrm{C}$ (lower $T_{\mathrm{m}}$ ) and $151^{\circ} \mathrm{C}$ (higher $T_{\mathrm{m}}$ ). The enthalpy of fusion $\left(\Delta H_{\mathrm{m}}\right)$, which relates to degree of crystallinity, was also decreased. Meanwhile, the glasstransition temperature $\left(T_{\mathrm{g}}\right)$ showed little change. It was revealed that small amounts of $3 \mathrm{HV}$ and $3 \mathrm{H} 4 \mathrm{MV}$ affected the $T_{\mathrm{m}}$ and the $\Delta H_{\mathrm{m}}$ of the PHA copolymers to a great extent.

\section{Discussion}

Previous studies showed that $3 \mathrm{H} 4 \mathrm{MV}$ unit which has iso-propyl side chain was incorporated into PHA from

Table 4 Thermal properties of PHA containing 3H4MV synthesized by the mutant 1F2 using leucine as a $3 \mathrm{H} 4 \mathrm{MV}$ precursor, $\mathrm{P}(3 \mathrm{HB}-\mathrm{co}-3 \mathrm{HV})$, and $\mathrm{P}(3 \mathrm{HB}-\mathrm{CO}-3 \mathrm{HHx})$

\begin{tabular}{|c|c|c|c|c|c|c|c|c|c|c|}
\hline \multirow[b]{2}{*}{ Polymer } & \multirow[b]{2}{*}{$\begin{array}{l}\text { Leucine } \\
\text { (g/L) }\end{array}$} & \multicolumn{4}{|c|}{ PHA composition $^{a}$} & \multicolumn{3}{|c|}{ Thermal property } & \multicolumn{2}{|c|}{ Molecular weight } \\
\hline & & $\begin{array}{c}3 \mathrm{HV} \\
(\mathrm{mol} \%)\end{array}$ & $\begin{array}{l}\text { 3H4MV } \\
\text { (mol\%) }\end{array}$ & $\begin{array}{c}3 \mathrm{HHx} \\
(\mathrm{mol} \%)\end{array}$ & $\begin{array}{l}\text { Total }^{\mathrm{b}} \\
\text { (mol\%) }\end{array}$ & $T_{\mathrm{m}}\left({ }^{\circ} \mathrm{C}\right)$ & $T_{\mathrm{g}}\left({ }^{\circ} \mathrm{C}\right)$ & $\Delta H_{\mathrm{m}}(\mathrm{J} / \mathrm{g})$ & $M_{\mathrm{n}}\left(\times 10^{3}\right)$ & $M_{w} / M_{n}$ \\
\hline $\begin{array}{l}\mathrm{P}(3 \mathrm{HB}-\mathrm{CO}-3 \mathrm{HV}-\mathrm{CO}- \\
3 \mathrm{H} 4 \mathrm{MV})^{\mathrm{C}}\end{array}$ & 0 & 1.6 & 0.8 & 0 & 2.4 & $\begin{array}{l}146 \\
159\end{array}$ & 3 & 42 & 250 & 1.9 \\
\hline $\begin{array}{l}\mathrm{P}(3 \mathrm{HB}-\mathrm{CO}-3 \mathrm{HV}-\mathrm{CO}- \\
3 \mathrm{H} 4 \mathrm{MV})^{\mathrm{C}}\end{array}$ & 5 & 2.3 & 1.0 & 0 & 3.3 & $\begin{array}{l}142 \\
154\end{array}$ & 3 & 40 & 251 & 1.8 \\
\hline $\begin{array}{l}\mathrm{P}(3 \mathrm{HB}-\mathrm{CO}-3 \mathrm{HV}-\mathrm{CO}- \\
3 \mathrm{H} 4 \mathrm{MV})^{\mathrm{C}}\end{array}$ & 10 & 1.2 & 3.1 & 0 & 4.3 & $\begin{array}{l}137 \\
151\end{array}$ & 3 & 42 & 98 & 1.6 \\
\hline$P(3 H B)^{d}$ & - & 0 & 0 & 0 & 0 & 172 & 4 & 77 & 224 & 2.1 \\
\hline $\mathrm{P}(3 \mathrm{HB}-\mathrm{CO}-3 \mathrm{HV})^{e}$ & - & 8 & 0 & 0 & 8 & 170 & - & 70 & - & - \\
\hline$P(3 H B-C O-3 H H x)^{f}$ & - & 0 & 0 & 5 & 5 & 151 & 0 & 69 & 100 & 1.9 \\
\hline
\end{tabular}

$M_{\mathrm{n}}$, number-average molecular weight; $M_{\mathrm{w}}$, weight-average molecular weight; $M_{\mathrm{w}} / M_{\mathrm{n}}$; polydispersity index; $T_{\mathrm{m}}$, melting temperature; $T_{\mathrm{g}}$ glass-transition temperature; $\Delta H_{\mathrm{m}}$, enthalpy of fusion.

a PHA compositions of purified copolymer samples were determined by GC. Copolymer compositions other than $3 \mathrm{HB}$ are shown.

b $3 \mathrm{HV}$ plus $3 \mathrm{H} 4 \mathrm{MV}$ plus $3 \mathrm{HHx}$ fraction.

c PHA synthesized by mutant $1 \mathrm{~F} 2$ from fructose $(20 \mathrm{~g} / \mathrm{L})$ and leucine $(0,5,10 \mathrm{~g} / \mathrm{L})$.

${ }^{\mathrm{d}} \mathrm{P}(3 \mathrm{HB})$ homopolymer synthesized by $R$. eutropha $\mathrm{H} 16$.

e (Scandola et al. 1992).

${ }^{f}$ (Doi et al. 1995). 
fructose as the sole carbon source (Tanadchangsaeng et al. 2009). However, the $3 \mathrm{H} 4 \mathrm{MV}$ fraction was too low $(0.5 \mathrm{~mol} \%)$ to improve the properties of $3 \mathrm{HB}$-based polymer. Thus we attempted to increase the $3 \mathrm{H} 4 \mathrm{MV}$ fraction by using $3 \mathrm{H} 4 \mathrm{MV}$ precursors. (Tanadchangsaeng et al. 2009) showed that 4-methylvalerate and 4-methyl2-pentenoate, which are branched fatty acids structurally similar to $3 \mathrm{H} 4 \mathrm{MV}$, were able to increase $3 \mathrm{H} 4 \mathrm{MV}$ fraction effectively. However, these precursors are not only costly but they also significantly inhibit bacterial cell growth. Therefore, we have sought a novel precursor able to be produced as a natural metabolite in bacterial cells such as branched amino acids.

There have been many reports on the use of amino acids to increase second monomer unit, especially $3 \mathrm{HV}$ unit, in 3HB-based PHA copolymer. It is known that isoleucine, threonine and valine are effective in increasing 3HV unit (Fujita et al. 1993; Kimura et al. 2003; Nakamura et al. 1992). These amino acids are partially converted to propionyl-CoA which is an intermediate of 3HV biosynthesis pathway in the cells (Steinbüchel and Pieper 1991). (Choi et al. 2003) demonstrated that the threonine-overproducing mutant of Alcaligenes sp. SH69 synthesized $\mathrm{P}(3 \mathrm{HB}-\mathrm{co}-3 \mathrm{HV})$ with $3 \mathrm{HV}$ fraction of up to $22 \mathrm{~mol} \%$ (3-fold higher than the parent strain) from glucose as the sole carbon source, without external amino acid supplementation. As seen from above, the amino acids have been widely used as $3 \mathrm{HV}$ precursors for $\mathrm{P}(3 \mathrm{HB}-\mathrm{co}-3 \mathrm{HV})$ synthesis. In contrast, there are no reports of $\mathrm{P}(3 \mathrm{HB}-\mathrm{co}-3 \mathrm{H} 4 \mathrm{MV})$ synthesis by using amino acids as a $3 \mathrm{H} 4 \mathrm{MV}$ precursor. (Tanadchangsaeng et al. 2009) showed that supplementation of $1 \mathrm{~g} / \mathrm{L}$ leucine had negative effect on $3 \mathrm{H} 4 \mathrm{MV}$ fraction. In this study, we also observed the negative effect on 3H4MV fraction at low concentration of leucine (1-5 g/L) in the parent strain (Figure 3a). However, supplementation of excess leucine (10-12 g/L) resulted in increased 3H4MV fraction (Table 1 and Figure 3a), suggesting that $3 \mathrm{H} 4 \mathrm{MV}$ unit can be derived from leucine.

Our results showed that leucine analog resistant mutant of $R$. eutropha was able to increase the 3H4MV fraction even when fructose was used as the sole carbon source (Figure 2 and Table 2). The leucine analog resistant $E$. coli has been employed to produce leucine as an extracellular product. The high leucine productivity of $3.4 \mathrm{~g} / \mathrm{L}$ was achieved by the $E$. coli mutants that are tolerable to $1 \mathrm{~g} / \mathrm{L}$ of leucine analog (4-azaleucine, Nakano et al. 1996). Unlike E. coli mutant, the four $R$. eutropha mutants generated in this study $(1 \mathrm{~F} 2,6 \mathrm{C} 1,12 \mathrm{D} 1$ and 13H3) did not secrete leucine to the culture medium, as revealed by HPLC analysis (data not shown). However, these mutants showed good growth even in the presence of $3 \mathrm{~g} / \mathrm{L}$ leucine analog. This concentration is 2 -fold higher than that used for the screening for leucine analog resistant mutants. In general, the mutants that were able to grow in high concentration of leucine analog have an impaired feedback system in leucine biosynthesis pathway, resulting in the overproduction of leucine. Therefore, the increased 3H4MV in the mutants observed here could be attributed to increased leucine production in the cells.

We presumed that the major difference between the parent strain and the four leucine analog resistant mutants $(1 \mathrm{~F} 2,6 \mathrm{C} 1,12 \mathrm{D} 1$ and $13 \mathrm{H} 3)$ is in the leucine biosynthesis pathway with or without feedback system. However, leucine supplementation $(10 \mathrm{~g} / \mathrm{L})$ to these cultures resulted in significantly different $3 \mathrm{H} 4 \mathrm{MV}$ fraction (Figure 3 and Table 3). This difference could not be explained by the leucine feedback system only. To eliminate the effect of mutation in the plasmid, we performed plasmid curing of the resistant mutant $1 \mathrm{~F} 2$ and then pBBR1" $\mathrm{C} 1_{\mathrm{Ps}} \mathrm{AB}$ Re plasmid was transformed again. The mutant harboring fresh plasmid showed the same dry cell weight, PHA content and PHA composition as the original strain (data not shown). Because the above four mutants were selected from leucine analog resistant library by HPLC assay based on 3H4MV fraction, they might have other mutations specifically in the $3 \mathrm{H} 4 \mathrm{MV}$ biosynthesis-related genes. Since $3 \mathrm{H} 4 \mathrm{MV}$ biosynthesis pathway has not yet been identified, these mutants might be useful in the study of this pathway.

PHA copolymers that were synthesized by the mutant 1F2 with leucine supplementation showed low melting temperatures, depending on $3 \mathrm{H} 4 \mathrm{MV}$ and $3 \mathrm{HV}$ fractions (Table 4). $\mathrm{P}(3 \mathrm{HB}-\mathrm{co}-3 \mathrm{HV})$ is the most popular 3HBbased copolymer, however, the incorporation of $8 \mathrm{~mol} \%$ $3 \mathrm{HV}$ unit into $\mathrm{P}(3 \mathrm{HB})$ sequences did not influence the melting temperature (Scandola et al. 1992). Meanwhile, only $5 \mathrm{~mol} \%$ of $3 \mathrm{HHx}$ was enough to decrease the melting temperature by $20^{\circ} \mathrm{C}$ (Doi et al. 1995). In this study, $4.3 \mathrm{~mol} \%$ of $3 \mathrm{H} 4 \mathrm{MV}$ and $3 \mathrm{HV}$ fractions had the same effect as $3 \mathrm{HHx}$ for decreasing the melting temperature by $20^{\circ} \mathrm{C}$. The effect of $3 \mathrm{H} 4 \mathrm{MV}$ on melting temperature was also demonstrated by the PHA copolymers synthesized by other types of bacteria (Chia et al, 2010; Lau et al 2010, 2011). In the hot melt processing of $\mathrm{P}(3 \mathrm{HB})$ materials, one of the major problems is the decrease in molecular weight of polymers due to rapid thermal degradation near its melting temperature. Reducing the melting temperature of the polymer allows for lower processing temperatures in the hot melt processing, without decreasing molecular weight. Therefore, 3HBbased copolymer containing small amount of $3 \mathrm{H} 4 \mathrm{MV}$ and $3 \mathrm{HV}$ fractions would be practical in terms of not only mechanical properties but also thermal properties.

In conclusion, this study demonstrated that $3 \mathrm{H} 4 \mathrm{MV}$ fraction in PHA can be increased by feeding excess leucine as a precursor of $3 \mathrm{H} 4 \mathrm{MV}$ unit or employing the 
leucine analog resistant mutants. Moreover, by combining these two factors, 3H4MV fraction was increased up to $3.1 \mathrm{~mol} \%$. This study is the first step in establishing the $\mathrm{P}(3 \mathrm{HB}-\mathrm{co}-3 \mathrm{H} 4 \mathrm{MV})$ biosynthesis from unrelated carbon sources such as sugars as the sole carbon source by focusing on the leucine metabolism.

\section{Acknowledgements}

This work was supported by the Grant-in aid for Industrial Technology Research Grant Program from the New Energy and Industrial Technology Development Organization (NEDO) of Japan and Research for Promoting Technological Seeds of Japan Science and Technology Agency (JST).

\section{Author details}

${ }^{1}$ Department of Innovative and Engineered Materials, Tokyo Institute of Technology, 4259 Nagatsuta, Midori-ku, Yokohama 226-8502, Japan 2Ecobiomaterial Research Laboratory, School of Biological Sciences, Universiti Sains Malaysia, 11800, Penang, Malaysia ${ }^{3}$ Bioplastic Research Team, RIKEN Biomass Engineering Program, 2-1 Hirosawa, Wako-shi, Saitama 351-0198, Japan

\section{Competing interests}

The authors declare that they have no competing interests.

Received: 21 April 2011 Accepted: 18 May 2011 Published: 18 May 2011

\section{References}

Bloembergen S, Holden DA, Hamer GK, Bluhm TL, Marchessault RH (1986) Studies of composition and crystallinity of bacterial poly( $\beta$-hydroxybutyrateco- $\beta$-hydroxyvalerate). Macromolecules 19:2865-2871. doi:10.1021/ ma00165a034.

Chia KH, Ooi TF, Saika A, Tsuge T, Sudesh K (2010) Biosynthesis and characterization of novel polyhydroxyalkanoate polymers with high elastic property by Cupriavidus necator PHB-4 transformant. Polym Degrad Stab 95:2226-2232. doi:10.1016/j.polymdegradstab.2010.09.011.

Choi GG, Kim MW, Kim JY, Rhee YH (2003) Production of poly(3-hydroxybutyrateco-3-hydroxyvalerate) with high molar fractions of 3-hydroxyvalerate by a threonine-overproducing mutant of Alcaligenes sp. SH-69. Biotecnol Lett 25:665-670. doi:10.1023/A:1023437013044

Doi Y, Kitamura S, Abe H (1995) Microbial synthesis and characterization of poly (3-hydroxybutyrate-co-3-hydroxyhexanoate). Macromolecules 28:4822-4828. doi:10.1021/ma00118a007.

Fujita M, Nakamura K, Kuroki H, Yoshie N, Inoue Y (1993) Biosynthesis of polyesters from various amino acids by Alcaligenes eutrophus. Int J Biol Macromol 15:253-255. doi:10.1016/0141-8130(93)90046-O.

Fukui T, Doi Y (1997) Cloning and analysis of the poly(3-hydroxybutyrate-co-3hydroxyhexanoate) biosynthesis gene of Aeromonas caviae. J Bacteriol 179:4821-4830

Kato M, Bao HJ, Kang CK, Fukui T, Doi Y (1996) Production of a novel copolyeste of 3-hydroxybutyric acid and medium-chain-length 3-hydroxyalkanoic acids by Pseudomonas sp. 61-3 from sugars. Appl Microbiol Biotechnol 45:363-370. doi:10.1007/s002530050697.

Kimura H, Mouri K, Takeishi M, Endo T (2003) Production and characterization of poly(3-hydroxybutyric acid-co-3-hydroxyvaleric acid) from L-valine by Ralstonia eutropha. Bull Chem Soc Jpn 76:1775-1781. doi:10.1246/ bcsj.76.1775.

Lau NS, Chee JY, Tsuge T, Sudesh K (2010) Biosynthesis and mobilization of a novel polyhydroxyalkanoate containing 3-hydroxy-4-methylvalerate monomer produced by Burkholderia sp. USM (JCM15050). Biores Technol 101:7916-7923. doi:10.1016/j.biortech.2010.05.049.

Lau NS, Tsuge T, Sudesh K (2011) Formation of new polyhydroxyalkanoate containing 3-hydroxy-4-methylvalerate monomer in Burkholderia sp. Appl Microbiol Biotechnol 89:1599-1609. doi:10.1007/s00253-011-3097-6.

Lee IY, Kim GJ, Choi DK, Yeon BK, Park YH (1996) Improvement of hydroxyvalerate fraction in poly( $\beta$-hydroxybutyrate-co- $\beta$-hydroxyvalerate) by a mutant strain of Alcaligenes eutrophus. J Ferm Bioeng 81:255-258. doi:10.1016/0922-338X(96)82217-3
Matsusaki H, Manji S, Taguchi K, Kato M, Fukui T, Doi Y (1998) Cloning and molecular analysis of the poly(3-hydroxybutyrate) and poly(3hydroxybutyrate-co-3-hydroxyalkanoate) biosynthesis genes in Pseudomonas sp. Strain 61-3. J Bacteriol 180:6459-6467

Matsusaki H, Abe H, Doi Y (2000) Biosynthesis and properties of poly(3hydroxybutyrate-co-3-hydroxyalkanoates) by recombinant strains of Pseudomonas sp. 61-3. Biomacromolecules 1:17-22. doi:10.1021/bm9900040.

Nakamura K, Goto Y, Yoshie N, Inoue Y (1992) Biosynthesis of poly(3hydroxyalkanoate) from amino acids. Int J Biol Macromol 14:321-325. doi:10.1016/S0141-8130(05)80072-8.

Nakano T, Ikeda M, Kino K, Furukawa S (1996) Process for producing L-leucine. JP1996-070879 (Japanese patent)

Rehm BHA (2003) Polyester synthases: natural catalysts for plastics. Biochem J 376:15-33. doi:10.1042/BJ20031254.

Scandola M, Ceccorulli G, Pizzoli M, Gazzano M (1992) Study of the crystal phase and crystallization rate of bacterial poly(3-hydroxybutyrate-co-3hydroxyvalerate). Macromolecules 25:1405-1410. doi:10.1021/ma00031a008.

Schlegel HG, Lafferty R, Krauss I (1970) The isolation of mutants not accumulating poly- $\beta$-hydroxybutyric acid. Arch Mikrobiol 71:283-294. doi:10.1007/BF00410161

Shimamura E, Kasuya K, Kobayashi G, Shiotani T, Shima Y, Doi Y (1994) Physical properties and biodegradability of microbial poly(3-hydroxybutyrate-co-3hydroxyhexanoate). Macromolecules 27:878-880. doi:10.1021/ma00081a041.

Singh AK, Mallick N (2009) Exploitation of inexpensive substrates for production of a novel SCL-LCL-PHA co-polymer by Pseudomonas aeruginosa MTCC 7925. $J$ Ind Microbiol Biotechnol 36:347-354. doi:10.1007/s10295-008-0503-x.

Steinbüchel A, Pieper U (1992) Production of a copolyester of 3-hydroxybutyric acid and 3-hydroxyvaleric acid from single unrelated carbon sources by a mutant of Alcaligenes eutrophus. Appl Microbiol Biotechnol 37:1-6

Sudesh K, Abe H, Doi Y (2000) Synthesis, structure and properties of polyhydroxyalkanoates: biological polyesters. Prog Polym Sci 25:1503-1555. doi:10.1016/S0079-6700(00)00035-6.

Tanadchangsaeng N, Kitagawa A, Yamamoto T, Abe H, Tsuge T (2009) Identification, biosynthesis, and characterization of polyhydroxyalkanoate copolymer consisting of 3-hydroxybutyrate and 3-hydroxy-4-methylvalerate Biomacromolecules 10:2866-2874. doi:10.1021/bm900696c

Tanadchangsaeng N, Tsuge T, Abe H (2010) Comonomer compositional distribution, physical properties, and enzymatic degradability of bacterial poly (3-hydroxybutyrate-co-3-hydroxy-4-methylvalerate) copolyester. Biomacromolecules 11:1615-1622. doi:10.1021/bm100267k.

Tsuge T, Kikkawa Y, Doi Y (2004) Microbial synthesis and enzymatic degradation of renewable poly[(R)-3-hydroxybutyrate-Co-(R)-3-hydroxyhexanoate]. Sci Technol Adv Mater 5:449-453. doi:10.1016/j.stam.2004.01.013.

Tsuge T, Yano K, Imazu S, Numata K, Kikkawa Y, Abe H, Taguchi S, Doi Y (2005) Biosynthesis of polyhydroxyalkanoate (PHA) copolymer from fructose using wild-type and laboratory-evolved PHA synthases. Macromol Biosci 5:112-117. doi:10.1002/mabi.200400152.

\section{doi:10.1186/2191-0855-1-6}

Cite this article as: Saika et al:: Enhanced Incorporation of 3-Hydroxy-4Methylvalerate Unit into Biosynthetic Polyhydroxyalkanoate Using Leucine as a Precursor. AMB Express 2011 1:6.

\section{Submit your manuscript to a SpringerOpen ${ }^{\circ}$ journal and benefit from:}

- Convenient online submission

- Rigorous peer review

- Immediate publication on acceptance

- Open access: articles freely available online

- High visibility within the field

- Retaining the copyright to your article

Submit your next manuscript at $>$ springeropen.com 